\title{
Editorial
}

\section{Balloon mitral valvuloplasty in the elderly}

Balloon mitral valvuloplasty has, over the last 15 years, become an established interventional procedure. For patients with pliable uncalcified mitral stenosis, dilatation with the Inoue balloon is the intervention of choice, offering results comparable to surgical commissurotomy. ${ }^{1}$ In the Western world, however, with the gradual extinction of rheumatic fever, patients with mitral stenosis are now almost exclusively elderly. Such patients tend to have calcified, thickened, and relatively immobile valves, often with significant subvalvar disease, and as such are theoretically unsuited to balloon valvuloplasty. ${ }^{2}{ }^{3}$ But even a small increase in mitral valve orifice may be adequate to allow an elderly person to regain their independence; therefore some have advocated undertaking the interventional option at low risk, with only moderate expectations, rather than opting for mitral valve replacement, with its significant perioperative morbidity and mortality. But is this approach justified?

In this issue of Heart, Sutaria and colleagues describe long term outcome for elderly patients undergoing balloon valvuloplasty at one high volume UK centre. ${ }^{4}$ Patients considered unsuitable for surgery - in whom the decision to offer valvuloplasty was therefore in some respects straightforward-had a relatively poor, though not surprising, event free survival rate of $25 \%$ at five years. Among those considered suitable for surgical treatment, one year survival free of death or mitral valve replacement, and with improvement in New York Heart Association class by at least one grade, was $64 \%$, falling to $36 \%$ at five years. By this stage, numbers were few. In the absence of a randomised trial of surgical versus interventional management of mitral stenosis in elderly patients (which is never likely to happen, and in which treatment arms could not be strictly comparable anyway ${ }^{5}$ ), mitral valvuloplasty would seem on this evidence to be a fair rather than a good option for elderly patients with mitral stenosis.

\section{Investigation}

The investigation of patients with symptomatic mitral stenosis centres around echocardiography. Mitral valve area (MVA), left atrial diameter, mitral regurgitation, and pulmonary artery pressure can all be gauged with reasonable accuracy from transthoracic imaging. "Scoring" of the valve according to the Wilkins' criteria-calcification, mobility, thickening, and subvalvar involvement-and assessment of commissural calcification can be made, and are good predictors of outcome. ${ }^{2}{ }^{3}$ Transoesophageal echocardiography is mandatory to exclude free atrial thrombus, and provides very clear images of the mitral apparatus. Since the development of transeoesophageal echocardiography therefore, right and left heart catheterisation has become outmoded as a means of assessment of the severity of mitral stenosis. Pulmonary capillary wedge pressure derived diastolic transmitral gradient in any case routinely overestimates stenosis severity. ${ }^{67}$ Cardiac catheterisation before referral for valvuloplasty merely exposes the patient to a further invasive procedure, the morbidity from which is greatest among the elderly. At our centre, the recommendation is for "one stop" cardiac catheterisation (leading to balloon mitral valvuloplasty if appropriate) on the basis of clinical and echocardiographic findings alone.
If at catheterisation the degree of mitral regurgitation or coronary disease is greater than suspected, surgical referral can be made as appropriate. If haemodynamics suggest mild stenosis only, no intervention is required and the patient may be spared a second invasive procedure. Otherwise, balloon valvuloplasty can proceed as planned.

On the basis of the echocardiogram, likelihood of procedural success can be assessed. Patients with grade 4 valvar calcification, severe commissural calcification or grade 4 subvalvar disease are unlikely to gain significant symptom relief from valvuloplasty, and surgical referral is preferable if appropriate. Otherwise, all comers can be consideredindividual patients may derive substantial clinical benefit even with a small increase in MVA, despite high total echocardiographic score.

But while accepting almost all comers for valvuloplasty may seem reasonable-there is a chance of clinical improvement in all, with a minimally invasive techniquethere is, however, a danger that the window of opportunity for a long lasting surgical solution may be missed. The patient who is fit for surgery but undergoes valvuloplasty may return with restenosis some years later frailer, older, and with more comorbidities - an altogether less attractive surgical option. These individuals - rather than those who are genuinely unfit for surgery - are the patients in whom the decision is difficult. In the end the patient, given the choice, often opts for the less invasive procedure, reasoning that surgery remains an option in the short term if the balloon fails to relieve their symptoms.

The technique of valvuloplasty is no different for elderly patients, but the procedure is often more of a technical challenge. Tortuous iliac vessels, huge atria, and distorted cardiac anatomy combine to make left atrial access more hazardous, while subvalvar disease and heavy valvar calcification test the self positioning capability and toughness of the Inoue balloon-nonetheless acknowledged as the instrument of choice. ${ }^{8}$

\section{Results and complications}

Results in the elderly are less impressive than in younger patients, but symptom resolution may still be good. In general, valve area may be expected to increase by $50 \%$ rather than the $100 \%$ usually achieved when dilating pliable valves. Haemodynamic success (defined as an increase in the MVA of $>50 \%$, with a final MVA $>1.5 \mathrm{~cm}^{2}$ and mitral regurgitation $\leqslant$ grade 2 ) may be expected in $50 \%$ of cases. ${ }^{910}$

As with all interventional procedures, complications are operator dependent. The learning curve is shallow ${ }^{11}$ and more than 10 procedures a year are probably required to maintain competence. The potential for complications is magnified in the elderly. Death is fortunately rare, but most series quote a major complication rate (death, cardiac tamponade, myocardial infarction, stroke, or emergency mitral valve replacement) of up to $10 \% .^{1012}{ }^{13}$ Acute severe mitral regurgitation in particular may be seen with greater frequency in the elderly, as the circular cross section of the Inoue balloon means that force is applied not only to the fused commissures, but also to the surrounding leaflet structures, which are more liable to fracture when heavily calcified. The recently developed metal commissurotome 
may prove useful in minimising this particular complication. ${ }^{14}$

There are few long term series in the elderly. Those that exist report three year event free survival in the region of $40 \%,{ }^{10}{ }^{13}$ results which are in keeping with the findings of Sutaria and colleagues. ${ }^{4}$ It is clear, therefore, that balloon valvuloplasty must be considered a palliative rather than definitive procedure, and it is important that this is understood by patients electing to undergo this treatment.

Restenosis following valvuloplasty, however, is a slow process. Defined as loss of more than $50 \%$ of the procedural gain in MVA, with MVA $<1.5 \mathrm{~cm}^{2}$, restenosis may be expected in $25 \%$ of patients over five years (Papworth Hospital, unpublished data, 1999). We therefore aim for a moderate increase in MVA, at low procedural risk, ${ }^{9}$ rather than strive for a substantial increase in valve area at significant risk.

The patient base to whom intervention is offered continues to broaden. As a result, patients increasingly present second time around. Those who have had previous commissurotomy reappear, typically in their $60 \mathrm{~s}$, with recurrent dyspnoea, and account for roughly a quarter of the workload in the UK. ${ }^{4}{ }^{9}$ Results in these patients, however, are in general less good. ${ }^{12}$ Patients who have had one successful valvuloplasty may return for further intervention after a number of years. Data on outcome among these patients is scarce, but there appears to be a law of diminishing returns, particularly in patients with less favourable valve anatomy. ${ }^{15}$ The pathophysiology of mitral restenosis does not consist solely of commissural re-fusion and therefore responds less well to a technique primarily intended for commissural splitting.

Other patient groups that have begun to appear for mitral valvuloplasty over the last few years include those with stenosed mitral valve bioprostheses, which may be dilated successfully in the short term, ${ }^{16}$ and those with metallic aortic valve replacements, who may undergo valvuloplasty via double transseptal puncture. ${ }^{17}$ Occasionally, patients with mitral stenosis present in cardiogenic shock $^{18}$ or with suprasystemic pulmonary artery pressures. The minimally invasive nature of balloon mitral valvuloplasty makes these patients ideally suited to interventional rather than surgical management.

\section{Conclusions}

Balloon mitral valvuloplasty is a palliative procedure which can offer symptom relief at acceptable risk for elderly patients. In contrast to mitral valve replacement, general anaesthesia, thoracotomy, and immobilisation are avoided, and this is a major advantage. Expectations of elderly patients are less, and requirements fewer; hence, small increases in MVA may be more than adequate to allow a return to independence. Restenosis rate is slow, and this argues against over zealous attempts to "crack" the valve. Complication rates in experienced hands are low, and, provided a window of opportunity for surgery is not being missed which might later be regretted, we suggest that consideration should be given to balloon mitral valvuloplasty for the majority of elderly patients with symptomatic mitral stenosis.

D J R HILDICK-SMITH L M SHAPIRO

Cardiac Unit,

Papworth Hospital

Cambridge CB3 $8 R E$

email:david.hildick-smith@papworth-tr.anglox.nhs.uk

1 Reyes VP, Raju BS, Wynne J, et al. Percutaneous balloon valvuloplasty compared with open surgical commissurotomy for mitral stenosis. N Engl f Med pared with open

2 Wilkins GT, Weyman AE, Abascal VM, et al. Percutaneous balloon dilatation of the mitral valve: an analysis of echocardiographic variables related to outcome and the mechanism of dilatation. Br Heart $\mathcal{f}$ 1988;60:299-308.

3 Cannan CR, Nishimura RA, Reeder GS, et al. Echocardiographic assessment of commissural calcium: a simple predictor of outcome after percutaneous mitral balloon valvotomy. I Am Coll Cardiol 1997;29:175-80.

4 Sutaria N, Elder AD, Shaw TRD. Long term outcome of percutaneous mitral balloon valvotomy in patients aged 70 and over. Heart 2000;83:433-

5 Bonchek LI. Randomised trials of new procedures: problems and pitfalls [editorial]. Heart 1997;78:535-6.

6 Hosenpud JD, McAnulty JH, Morton MJ. Overestimation of mitral valve gradients obtained by phasic pulmonary capillary wedge pressure. Cathet Cardiovasc Diagn 1983;9:283-90.

7 Hildick-Smith DJR, Walsh JT, Shapiro LM. Pulmonary capillary wedge pressure in mitral stenosis accurately reflects mean left atrial pressure but overestimates transmitral gradient. Am $\mathcal{F}$ Cardiol In press.

8 Shaw TR, Turnbull CM, Currie P, et al. A comparison of cylindrical and Inoue balloon techniques for mitral valvotomy in patients in the United Kingdom. Br Heart f 1994;72:486-91

9 Shapiro LM, Hassanein H, Crowley JJ. Mitral balloon valvuloplasty in patients $>70$ years of age with severe mitral stenosis. Am $\mathcal{f}$ Cardiol 1995;75:633-6.

10 Tuzcu EM, Block PC, Griffin BP, et al. Immediate and long-term outcome of percutaneous mitral valvotomy in patients 65 years and older. Circulation 1992;85:963-71.

11 Rihal CS, Nishimura RA, Holmes DR, Jr. Percutaneous balloon mitral valvuloplasty: the learning curve. Am Heart F 1991;122:1750-6.

12 Palacios IF, Tuzcu ME, Weyman AE, et al. Clinical follow-up of patients undergoing percutaneous mitral balloon valvotomy. Circulation 1995;91: 671-6.

13 Iung B, Cormier B, Farah B, et al. Percutaneous mitral commissurotomy in the elderly. Eur Heart $\mathcal{F}$ 1995;16:1092-9.

14 Cribier A, Eltchaninoff H, Koning R, et al. Percutaneous mechanical mitral commissurotomy with a newly designed metallic valvulotome: immediate results of the initial experience in 153 patients. Circulation 1999;99:793-9.

15 Pathan AZ, Mahdi NA, Leon MN, et al. Is redo percutaneous mitral balloon Pathan AZ, Mahdi NA, Leon MN, et al. Is redo percutaneous mitral balloon
valvuloplasty (PMV) indicated in patients with post-PMV mitral valvuloplasty (PMV) indicated in patien
restenosis? f Am Coll Cardiol 1999;34:49-54.

16 Ludman PF, Pitt MP. Images in cardiology: Inoue balloon dilatation of a mitral valve prosthesis. Heart 1999;81:320.

7 Hildick-Smith DJR, Shapiro LM. Balloon mitral valvuloplasty employing double transseptal puncture. Cathet Cardiovasc Diagn 1998;45:33-6.

18 Goldman JH, Slade AK, Clague JR. Cardiogenic shock secondary to mitral stenosis treated by balloon mitral valvuloplasty. Cathet Cardiovasc Diagn 